${ }^{10}$ I grapple with this surprisingly complex issue in "Equal Consideration and Unequal Moral Status" (manuscript under review).

${ }^{11}$ He does, however, sometimes use them. See, e.g., $A L$, 228 and 229.

${ }^{12}$ For an attempted refutation of extreme anti-intuitionism, see my Interests, Intuition, and Moral Status (a 1989 Georgetown University dissertation), ch. 3.

${ }^{13}$ R. M. Hare, Moral Thinking: Its Levels, Method, and Point (Oxford: Clarendon, 1981).

14 "Reasoning towards Universalizability," in Douglas Seanor and N. Fotion, eds., Hare and Critics: Essays on Moral Thinking (Oxford: Clarendon, 1988), p. 147. Actually, in this article Singer suggests that Hare's case needs some supplemental reasoning, which he attempts to provide. In doing so, he notes that "placing a restriction on universalizability does not seem to involve an inconsistency in any strict logical sense" (p. 157) (see discussion of the "sui generis view" above); he thinks instead that such a restriction is arbitrary. While he imagines a counter to the charge of arbitrariness (pp. 158-159), the interlocutor is not very resourceful. In any event, Singer's supplemental argumentation cannot save Hare's theory if the latter fails for other reasons, as I (and most other moral philosophers) think.

${ }^{15}$ For some weighty arguments against Hare's view, see R. B. Brandt, "Act-Utilitarianism and Metaethics,"Thomas Nagel, "The Foundations of Impartiality," and Bernard Williams, "The Structure of Hare's Theory," in Hare and Critics.

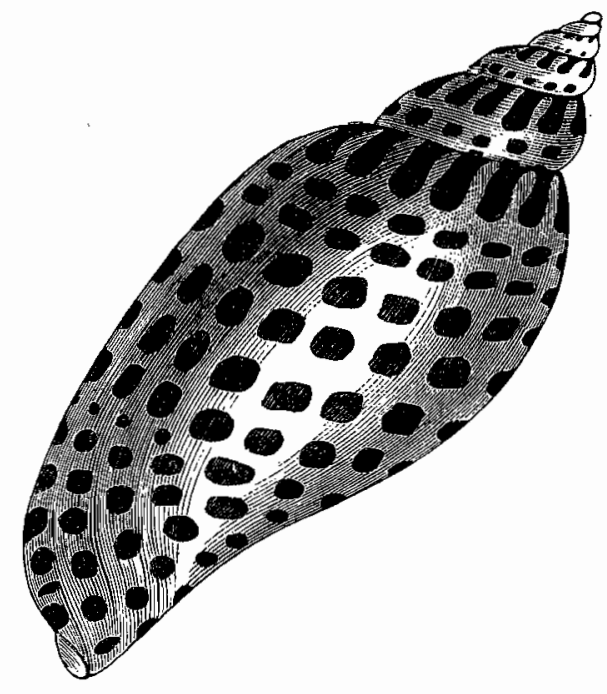

\section{A Response to David DeGrazia}

\section{Peter Singer Monash University}

My first reaction, on reading David DeGrazia's review of the second edition of Animal Liberation, was to applaud. He has located the strengths and weaknesses of the book with a rare precision. If his praise is too generous, I shall leave it to others to take him to task over that. To me, it is particularly pleasing because it is not the praise of an uncritical admirer. Nor did my urge to applaud fade away when I turned to the final, most critical, section of the review, for here I found DeGrazia's criticisms do indeed point to aspects of the book's argument that are, at best, incompletely developed.

DeGrazia is right to say that some of his criticisms go more deeply into philosophical theory than I wanted to do in $A L$. When I came to write the second edition, I knew that there was now a mass of sophisticated philosophical literature on the topic that had not existed when I wrote the first edition. At first I planned to respond to it, but I soon realized that if I were to do so, I would be writing a different, and much less readable, book. That was something I did not want to do. I vaguely intend to write a comprehensive "reply to my critics" on some future occasion; meanwhile other projects fill my time, projects more stimulating and, I think, more fruitful than the tedious prospect of exposing the flaws in a volley of objections, some of which are of interest only insofar as they provide evidence of the lengths to which intelligent people with philosophical training can go in order to avoid the need to change their diet.

I do not, however, include in the scope of that last sentence the difficulties to which DeGrazia points in the final part of his review. The matters to which he

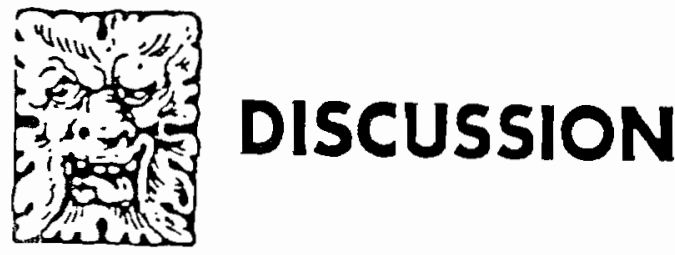


refers are of real philosophical interest and are central to my approach to the ethics of our relations with animals. So I shall try to say something about them.

First, DeGrazia presents a challenge to the principle of equal consideration of interests which he refers to as "the argument from social bondedness." My response to this challenge, as presented by Mary Midgley and more recently by Jeffrey Gray, ${ }^{1}$ is indeed the one DeGrazia describes as "Singerian." This DeGrazia suggests is not good enough, because "many clearthinking philosophers" will not be satisfied by it. Like W. D. Ross, they will think that the nature of the relationship of the parent and child in itself justifies preferential treatment, and any overall benefits are fortuitous.

I don't think that these philosophers have thought clearly enough. If they had, they would have discarded the kind of ethical intuitionism espoused by Ross, because they would have realized that our intuitions are not a reliable guide to what we, as reflective reasoning beings, can justify. After all, for most of human history almost all males (and probably even most females) have thought that the nature of the relationship of the husband and wife, in itself, requires obedience on the part of the wife. And as recently as the turn of the century, Hastings Rashdall, one of the most distinguished British philosophers of his day, thought that the self-evident wrongness of sexual permissiveness was a decisive objection to any form of hedonistic utilitarianism. ${ }^{2}$

When we look at the specific relationship to which Midgley and DeGrazia refer-the relationship between parent and child-it is true that there are very strong natural feelings associated with this relationship. That is, of course, why it is so much better that parents should normally be responsible for the welfare of their own children: Their natural feelings will lead them to fulfill the task far better than any impersonal system of social welfare. But if we allow strong natural feelings to be a sufficient basis for the derivation of moral rights and obligations, we will be in serious trouble, as even a cursory glance at race relations in many different countries will show.

The second challenge, the view that being human just is a morally relevant characteristic, is logically troubling. DeGrazia gets it exactly right, however, when he says that although a defence of the claim that humans deserve greater consideration than animals is not logically required to refer to any traits about humans beyond the fact that they are human, no satisfactory defence of this claim could limit itself to this fact. DeGrazia is tentative about this. His hesitations might be overcome if he were to consider that the notion of what it is to be "human" is neither transparent nor uncontroversial, as we can see when we look at discussions of the status of the human embryo, of anencephalic humans, and of those whose brains have irreversibly ceased to function, either as a whole or in those sections responsible for consciousness. When the proponents of what DeGrazia calls the "sui generis view" are forced to come clean on what they mean by "human," their case begins to unravel. If, in the end, they come down to mere membership of the species Homo sapiens, they should be asked whether the discovery that green-eyed people are in fact a different species (though in every aspect of their mental and emotional lives just like humans) would mean that green-eyed people are not entitled to the same consideration as the rest of us. There is, of course, no knockdown logical objection to saying that, in that hypothetical situation, we would indeed be entitled to treat green-eyed people with less consideration than others. But now the arbitrariness of the species boundary is so glaring that no one will find such an answer convincing.

In objecting to my failure to explain what equal consideration comes to, DeGrazia makes one minor error that should be corrected. After quoting my view that it is not arbitrary to hold that different lives many have different values, he adds: "I assume this means that the life of a normal adult human and that of a mouse are not to be given equal consideration, for if one must choose between them, one should, on this view, save the human." The conclusion is right, but the first part of the assumption is loosely put; one should give the mouse and the human equal consideration (that is, the scales by which one compares what the human gets out of life and what the mouse gets out of life should be impartial), but the upshot of that equal consideration will be, I suggest, that we value the life of the normal human more highly than that of the mouse, because from an impartial perspective, the normal human does have more to lose. So there is no question of "what determines whether two interests, or sets of interests, are identical or sufficiently similar that equal consideration applies to them." As I indicated in Practical Ethics (p. 92, although not quite in these words), I should be willing to give equal consideration 
to the lives of the weeds I pull out of my garden. It is just that when I do so, and put myself in their place, using the best available knowledge about what it is like to be a weed pulled out of a garden, I decide that the life of the weed is a complete blank; it has no experiences, and so has nothing to lose. Equal consideration of my interest in growing tomatoes and the weed's "interest" in living, is perfectly appropriate, but since it reveals that the weed has no interest in living, it will always favor my interest in growing tomatoes.

I hope that I am not here using a linguistic device to avoid a substantive objection. If, as I suspect, DeGrazia is here raising, in less than entirely precise language, the point that it is very difficult to compare different interests across species, and hence very difficult to determine when one interest is or is not equal to another, I can only agree. But we just have to try our best, in much the same way that, when choosing within our own family, we have to try our best to determine when one child's interest in going to the beach is or is not equal to another child's interest in visiting the new skateboard ramp.

If this is not the place for DeGrazia to review the many objections made to act-utilitarianism, it is certainly not the place for me to defend it. I think, in hindsight, that-given my aim of writing $A L$ so that it could be accepted by people with a wide variety of ethical views-I should have been more cautious in my phrasing of the passage on p. 85 which DeGrazia quotes as establishing "fairly clearly" my actutilitarianism. To the objection that an experiment on a single animal might save many lives, it would have been enough to present my opponents with a choice: either they accept that in those circumstances it would also be right to perform the experiment on a braindamaged human, or they deny that it is justifiable to perform the experiment on any sentient third party, human or nonhuman.

The underlying ethical issue still remains: What should we think of utilitarianism in general, and of act-utilitarianism in particular? Since I accept much of what R. M. Hare says about the distinction between everyday moral thinking and the level of critical reflection on morality (see his Moral Thinking), ${ }^{3} \mathrm{I}$ am not sure if I should be regarded as an act-utilitarian. I originally accepted that label because I knew that 1 was not a rule-utilitarian; now, fortunately, utilitarians have a number of interesting options from which to choose. I remain, however, a utilitarian, and on that issue my differences with DeGrazia do, as he indicates, reflect our different views about the status of moral intuitions, and ultimately, about the basis of ethics. Since that topic continues to challenge me, I hope, eventually, to have more to say on it. But that will have to wait.

\section{Notes}

${ }^{1}$ See Jeffrey A. Gray, "On the morality of speciesism" and Peter Singer, "Speciesism, morality and biology: a response to Gray," The Psychologist (May, 1991).

${ }^{2}$ Hastings Rashdall, The Theory of Good and Evil, vol. 1 (Oxford: Clarendon Press, 1907), p. 197.

${ }^{3}$ R. M. Hare, Moral Thinking (Oxford: Oxford University Press, 1981), Pt. 1.

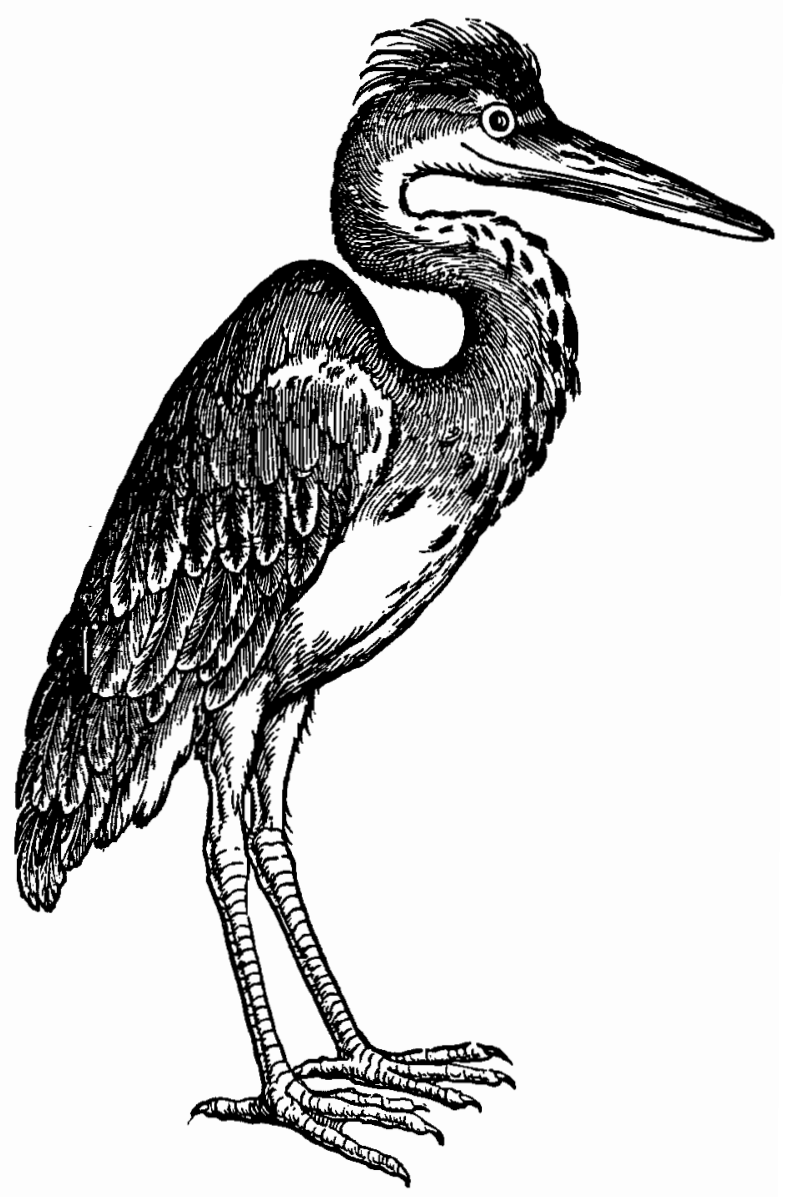

